\title{
Barriers to advanced manufacturing technology in small-medium enterprises (SMEs) in Malaysia
}

\begin{abstract}
Manufacturing companies strive to be competitive through the use of Advanced Manufacturing Technologies (AMT). AMT implementation is not simple with many barriers to its success, especially for smaller companies. These issues limit the access of small medium enterprises (SMEs) to the full benefits of the technology. This study is aimed to identify the barriers to successful AMT implementation in SMEs before improvement steps can be taken. A survey on the barriers was conducted on manufacturing SMEs in the Klang Valley region of Malaysia. From the results, a list of barriers was obtained and its severity ranked. The results showed that the lack of appropriate or proper training as the most severe barrier. The results may assist SMEs in understanding the state of Malaysian SMEs in implementing AMT and could serve as a guide to strategize solutions to overcome the barriers.
\end{abstract}

Keyword: Advanced manufacturing technology (AMT); Barriers; Implementation; Smallmedium enterprises (SMEs) 